\title{
AN ANALYSIS OF BORAX CONTENT IN LABELED AND BULK CHICKEN NUGGETS SOLD
} AT TRADISIONAL MARKETS OF SURABAYA

\author{
Indriani Puspitasari, Suprijandani, Didik Sugeng Purwanto
}

\begin{abstract}
Foodstuff constitutes any things come from biological resources and water, both processed and unprocessed. One of those processed foods is chicken nugget. Nugget is a processed animal product that is included in the category of easily damaged by microorganisms. Therefore, in order obtain the desired quality of food, the manufacturers often use a forbidden additional material such as borax that is commonly used in glass, fungicide, herbicide and insecticide industries.

This study is a descriptive type of study with cross sectional approach that is aimed to learn about borax content in labeled and bulk chicken nuggets sold at tradisional markets of Surabaya. The study is located at 10 traditional markets managed by PD Pasar Surya and 10 markets managed individually.

The result of study indicates that from the organoleptic test of 12 samples of labeled chicken nugget, 4 samples $(33,3 \%)$ are hard and rubbery, 3 sampel $(25 \%)$ do not have the natural aroma of chicken meat, 6 samples $(50 \%)$ have duller color and 2 samples $(16,6 \%)$ have all those three characteristics. Meanwhile, among 20 sampel of bulk chicken nugget, 14 samples $(70 \%)$ are hard and rubbery, 14 samples $(70 \%)$ do not have the natural aroma of chicken meat, 7 samples (35\%) have duller color, and 6 samples $(30 \%)$ have all those three characteristics. However, such an organoleptic test does not fully indicate the existence of borax. A qualitative laboratory test by means of Turmeric Yellow Paper Test then is required. It is found in the laboratory examination that 3 samples (25\%) out of 12 samples of labeled chicken nugget positively contain borax and 7 samples (35\%) out of 20 samples of bulk chicken nugget positively contain borax.

The market manager should cooperate with the relevant service to perform a periodic food control. The public needs to learn about the characteristics of nugget with borax. Other researchers are wished to do a qualitative test of borax content on other food products or an experiment to maintain the quality of nugget with no dangerous chemical such as borax.
\end{abstract}

\section{Keywords : Borax, labeled chicken nugget, bulk chicken nugget}

\section{PENDAHULUAN}

Bahan makanan atau pangan adalah segala sesuatu yang berasal dari sumber hayati dan air, baik yang diolah maupun tidak diolah (Saparinto, 2006). Makanan olahan yang sering dikonsumsi masyarakat adalah nugget.

Nugget adalah produk olahan hewani yang dicetak, dimasak dan dibekukan, dibuat dari campuran daging ayam giling (SNI 016683-202). Dalam penyimpanannya, makanan ini selalu di simpan dalam kondisi beku (frozen). Nugget merupakan hasil produk olahan hewani yang masuk dalam kategori mudah rusak oleh mikroorganisme. Maka untuk mendapatkan kualitas makanan seperti yang diinginkan tak jarang produsen makanan menggunakan bahan tambahan makanan yang dilarang.

Dalam Permenkes RI No 1168/Menkes/Per/X/1999 tentang bahan tambahan makanan menyebutkan bahwa Bahan Tambahan makanan Yang Dilarang Digunakan Dalam Makanan adalah Asam Borat. Asam borat $\left(\mathrm{H}_{3} \mathrm{BO}_{3}\right)$ merupakan senyawa boron yang dikenal juga dengan nama boraks (Cahyadi, 2008). Boraks sebenarnya merupakan pembersih, fungisida, herbisida dan insektisida yang bersifat toksik atau meracun untuk manusia (Nurheti, 2007).

Umumnya, pasar tradisional menyediakan bahan-bahan makanan pokok dan makanan olahan seperti nugget. Nugget yang 
diperdagangkan dipasar tradisional terdiri dari nugget berlabel dan nugget curah. Berdasarkan survei pendahuluan yang dilakukan oleh penulis pada tanggal 24 Februari 2013 di pasar tradisional Surabaya yang diambil secara uji petik pada 4 sampel nugget yang terdiri dari 2 nugget curah dan 2 nugget berlabel, didapatkan hasil bahwa 1 sampel nugget curah memiliki keadaan fisik secara organoleptik berbentuk kenyal dan padat, nugget berbau tidak alami (daging ayam) atau apek, dan warna nugget lebih kusam dari warna asli nugget. Dari pengamatan ini memberikan dugaan bahwa 1 sampel nugget curah tersebut positif mengandung boraks. Dugaan ini diperkuat dengan hasil pemeriksaan laboratorium di Laboratorium Kesehatan Dinas Kesehatan Surabaya pada tanggal 25 Februari 2013, bahwa 1 sampel nugget curah positif mengandung boraks. Tujuan penelitian ini yaitu untuk mengetahui kandungan boraks pada nugget berlabel dan nugget curah yang dijual di pasar tradisional Surabaya.

\section{METODA PENELITIAN}

\section{Jenis Penelitian}

Berdasarkan analisis data, penelitian ini termasuk deskriptif. Berdasarkan waktu, penelitian ini termasuk cross sectional.

\section{Lokasi dan Waktu Penelitian}

Lokasi pengambilan sampel nugget ayam dilakukan di pasar tradisional Surabaya dengan cara purposif (purposive sampling) (Soekidjo, 2010) dengan pertimbangan pasar tradisional yang memiliki pedagang nugget berlabel dan curah. Penelitian dilaksanakan pada bulan Maret - Juli 2013.

\section{Populasi, Sampel, dań Besar Sampel \\ Populasi dalam penelitian ini adalah seluruh nugget ayam yang di jual oleh pedagang nugget dengan kriteria pasar yang memiliki pedagang nugget ayam berlabel dan nugget ayam curah. Sampel nugget ayam diambil dari pedagang nugget yang menjual nugget ayam berlabel dan nugget curah di 10 pasar tradisional yang dikelola PD Pasar Surya dan Swasta. Untuk setiap pedagang nugget diambil 2 sampel nugget terdiri dari 1 sampel nugget ayam berlabel dan 1 sampel nugget ayam curah. Berdasarkan hasil observasi didapatkan 12 nugget berlabel dan 20 sampel nugget curah.}

Variabel dan definisi operasional
Variabel Penelitian dalam penelitian ini adalah kondisi fisik nugget, dan kandungan boraks pada nugget berlabel dan nugget curah. Definisi Operasional dalam penelitian ini adalah kondisi fisik nugget, kandungan boraks pada nugget berlabel dan nugget curah, uji organoleptik, nugget berlabel, nugget curah, nugget, pasar

\section{Cara Pengumpulan Data}

Data diperoleh dari hasil wawancara pada pedagang nugget ayam berlabel dan nugget ayam curah menggunakan lembar wawancara, melakukan pengamatan fisik nugget secara organoleptik menggunakan lembar observasi dan melakukan pengambilan sampel nugget ayam di pasar tradisional Surabaya untuk pemeriksaan kandungan boraks secara kualitatif di Laboratorium Kesehatan Dinas Kesehatan Surabaya.

\section{Metode Analisis Data}

Data dari hasil wawancara, observasi, dan hasil dari pemeriksaan laboratorium akan disajikan dalam bentuk tabel yang kemudian akan dianalisis secara deskriptif dibandingkan dengan Peraturan Menteri Kesehatan RI No. 1168/ Menkes/Per/X/1999 agar dapat ditarik sebuah kesimpulan dari seluruh analisis yang telah dilakukan.

\section{HASIL PENELITIAN DAN PEMBA- HASAN \\ Hasil Wawancara \\ Berdasarkan hasil wawancara pada 20} pedagang di 20 pasar tradisional didapatkan hasil bahwa nugget ayam curah yang dijual berasal dari beberapa wilayah di Surabaya, Madura, dan Sidoarjo. Sedangkan untuk nugget ayam berlabel diambil dari beberapa label dagang nugget yang berbeda - beda yang berasal dari Pasuruan, Serang, Bogor, dan Tangerang. Jumlah nugget yang disediakan pedagang perhari sebanyak $2-8$ bungkus nugget ayam berlabel, sedangkan untuk nugget ayam curah menyediakan $4-10$ bungkus.

Dari wawancara diketahui bahwa nugget ayam yang tidak habis terjual disimpan di kantong plastik (45\%), disimpan di kardus (40\%), dan hanya $15 \%$ disimpan di chiller (alat pendingin untuk menyimpan makanan), padahal nugget ayam merupakan produk olahan hewani yang mudah rusak oleh mikroorganisme, sehingga suhu pembekuan yang digunakan 
bisa sampai dibawah $-18^{\circ} \mathrm{C}$

(Purnawijayanti, 2001).

Setiap harinya sebanyak $70 \%$ pedagang menerima kiriman nugget ayam berlabel, dan $90 \%$ pedagang menerima kiriman nugget ayam curah. Sebanyak $85 \%$ pedagang mengatakan nugget ayam curah lebih disukai oleh konsumen dan dimanfaatkan untuk pemeriksaan makanan.

\section{Hasil Observasi Pemeriksaan Secara Fisik Kandungan Boraks Pada Nugget Ayam Berlabel dan Curah Yang Dijual di Pasar Tradisonal Surabaya.}

Pemeriksaan secara fisik kandungan Boraks pada nugget ayam yang dijual di Pasar Tradisional Surabaya dilakukan berdasarkan ciri-ciri kandungan boraks di dalamnya.

Tabel 1

Hasil Pemeriksaan Fisik Nugget Ayam Berlabel Yang Di Jual Oleh Pedagang Nugget di Pasar Tradisional Surabaya

\begin{tabular}{|c|c|c|c|c|c|}
\hline \multirow[b]{2}{*}{ Kode Sampel } & \multirow[b]{2}{*}{ Nama Pasar } & \multicolumn{3}{|c|}{$\begin{array}{l}\text { Ciri-ciri Kandungan Boraks pada Nugget } \\
\text { Berlabel }\end{array}$} & \multirow[b]{2}{*}{$\begin{array}{l}\text { Hasil } \\
\text { Pemeriksaan } \\
\text { Secara Fisik }\end{array}$} \\
\hline & & $\begin{array}{l}\text { Berbentuk } \\
\text { Kenyal dan } \\
\text { Padat (Tidak } \\
\text { mudah } \\
\text { hancur) }\end{array}$ & $\begin{array}{l}\text { Berbau tidak } \\
\text { alami (daging } \\
\text { ayam) atau } \\
\text { apek }\end{array}$ & $\begin{array}{l}\text { Bewarna lebih } \\
\text { kusam dari } \\
\text { warna asli }\end{array}$ & \\
\hline PA - L1 & Asemrowo & Positif & Positif & Positif & Positif 3 \\
\hline PB - L2 & Bulak Banteng & Negatif & Negatif & Negatif & Negatif \\
\hline$P C$ - L3 & Dinoyo tangsi & Positif & Positif & Negatif & Positif 2 \\
\hline PD - L5 & Gunung Sari & Negatif & Negatif & Negatif & Negatif \\
\hline PE - L6 & Indrakilla & Negatif & Negatif & Negatif & Negatif \\
\hline$P F-L 8$ & Kedinding & Negatif & Negatif & Positif & Positif 1 \\
\hline$P G$ - L11 & Pacarkeling & Negatif & Negatif & Positif & Positif 1 \\
\hline PH - L13 & Ploso & Positif & Negatif & Positif & Positif 2 \\
\hline PI - L16 & Sidotopo & Negatif & Negatif & Positif & Positif 1 \\
\hline P] - L17 & Simo & Positif & Positif & Positif & Positif 3 \\
\hline PK - L19 & Soponyono & Negatif & Negatif & Negatif & Negatif \\
\hline$P L-L 20$ & Wonokromo & Negatif & Negatif & Negatif & Negatif \\
\hline
\end{tabular}

Berdasarkan hasil pemeriksaan fisik secara organoleptik pada nugget berlabel yang ada dalam tabel 1 terdapat ciri nugget mengandung boraks yaitu nugget berbentuk kenyal dan padat sebanyak 4 sampel $(33,3 \%)$.
Untuk ciri nugget berbau tidak alami (daging ayam) atau apek terdapat 3 sampel (25\%) nugget berlabel. Sedangkan untuk ciri nugget bewarna lebih kusam dari warna asli, sebanyak 6 sampel nugget berlabel (50\%). Sedangkan 5 sampel nugget belabel tidak terdapat ciri tersebut. 
Tabel 2

Hasil Pemeriksaan Nugget Ayam Curah Yang Di Jual Oleh Pedagang Nugget di Pasar Tradisional Surabaya

\begin{tabular}{|c|c|c|c|c|c|}
\hline \multirow[b]{2}{*}{ Kode Sampel } & \multirow[b]{2}{*}{ Nama Pasar } & \multicolumn{3}{|c|}{ Ciri-ciri Kandungan Boraks pada Nugget Curah } & \multirow[b]{2}{*}{$\begin{array}{l}\text { Hasil } \\
\text { Pemeriksaan } \\
\text { Secara Fisik }\end{array}$} \\
\hline & & $\begin{array}{l}\text { Berbentuk Kenyal } \\
\text { dan Padat (Tidak } \\
\text { mudah hancur) }\end{array}$ & $\begin{array}{l}\text { Berbau tidak } \\
\text { alami (daging } \\
\text { ayam) atau } \\
\text { apek }\end{array}$ & $\begin{array}{l}\text { Bewarna lebih } \\
\text { kusam dari } \\
\text { warna asli }\end{array}$ & \\
\hline PA - C1 & Asemrowo & Positif & Negatif & Negatif & Positif 1 \\
\hline $\mathrm{PB}-\mathrm{C2}$ & Bulak Banteng & Negatif & Positif & Negatif & Positif 1 \\
\hline PC - C3 & Dinoyo Tangsi & Positif & Positif & Positif & Positif 3 \\
\hline PD - C4 & Donorejo & Positif & Positif & Negatif & Positif 2 \\
\hline PE - C5 & Gunung Sari & Negatif & Negatif & Negatif & Negatif \\
\hline PF - C6 & Indrakilla & Positif & Positif & Positif & Positif 3 \\
\hline PG - C7 & Kalianyar & Positif & Negatif & Negatif & Positif 1 \\
\hline $\mathrm{PH}-\mathrm{C8}$ & Kedinding & Positif & Positif & Positif & Positif 3 \\
\hline PI - C9 & Kendang sari & Negatif & Negatif & Negatif & Negatif \\
\hline PJ - C10 & Manyar & Positif & Positif & Negatif & Positif 2 \\
\hline PK - C11 & Pacarkeling & Positif & Positif & Negatif & Positif 2 \\
\hline$P L-C 12$ & Paing & Positif & Positif & Negatif & Positif 2 \\
\hline PM - C13 & Ploso & Positif & Positif & Negatif & Positif 2 \\
\hline PN - C14 & Pucang anom & Positif & Positif & Positif & Positif 3 \\
\hline PO - C15 & Pogot & Negatif & Negatif & Negatif & Negatif \\
\hline PP - C16 & Sidotopo & Positif & Positif & Positif & Positif 3 \\
\hline$P Q-C 17$ & Simo & Positif & Positif & Positif & Positif 3 \\
\hline PR - C18 & Sutorejo & Positif & Positif & Negatif & Positif 2 \\
\hline PS - C19 & Soponyono & Negatif & Positif & Positif & Positif 2 \\
\hline PT - C20 & Wonokromo & Negatif & Negatif & Negatif & Negatif \\
\hline
\end{tabular}

Menurut hasil pemeriksaan fisik secara organoleptik dalam tabel 2, terdapat 14 sampel nugget (70\%) memiliki bentuk yang kenyal dan padat, 14 sampel nugget $(70 \%)$ memiliki bau apek dan berbau tidak alami daging, dan 7 sampel nugget (35\%) yang memiliki warna kusam dari warna asli nugget, sedangkan 6 sampel (30\%) tidak memiliki ciri tersebut. Namun demikian pemeriksaan terhadap ciri fisik ini harus diikuti dengan pemeriksaan laboratorium untuk lebih memastikan bahwa nugget tersebut mengandung boraks atau tidak. 


\section{Hasil Keterkaitan Uji Organoleptik Dengan Uji Laboratorium Tentang Kandungan Boraks Pada Nugget Berlabel Dan Nugget Curah Yang Dijual Di Pasar Tradisional Surabaya}

Tabel 3

Hasil Uji Organoleptik dengan Uji Laboratorium Terhadap Kandungan Boraks Pada Nugget Ayam Berlabel yang Dijual Di Pasar Tradisional Surabaya

\begin{tabular}{|c|c|c|c|c|c|}
\hline \multirow{3}{*}{$\begin{array}{c}\text { Kode Sampel } \\
\text { PA - L1 }\end{array}$} & \multicolumn{3}{|c|}{ Ciri-ciri Kandungan Boraks pada Nugget Berlabel } & \multirow{3}{*}{$\begin{array}{l}\text { Hasil } \\
\text { Pemeriksaan } \\
\text { Secara Fisik } \\
\text { Positif } 3\end{array}$} & \multirow{3}{*}{$\begin{array}{l}\text { Hasill Uji } \\
\text { Laboratorium } \\
\text { Positif }\end{array}$} \\
\hline & $\begin{array}{l}\text { Berbentuk Kenyal } \\
\text { dan Padat (Tidak } \\
\text { mudah hancur) }\end{array}$ & $\begin{array}{l}\text { Berbau tidak } \\
\text { alami (daging } \\
\text { ayam) atau apek }\end{array}$ & $\begin{array}{l}\text { Bewarna lebih } \\
\text { kusam dari } \\
\text { warna asil }\end{array}$ & & \\
\hline & Positif & Positif & Positif & & \\
\hline PB - L2 & Negatif & Negatif & Negatif & Negatif & Negatif \\
\hline PC - L3 & Positif & Positif & Negatif & Positif 2 & Positif \\
\hline$P D$ - L5 & Negatif & Negatif & Negatif & Negatif & Negatif \\
\hline PE - L6 & Negatif & Negatif & Negatif & Negatif & Negatif \\
\hline$P F-L 8$ & Negatif & Negatif & Positif & Positif 1 & Negatif \\
\hline PG - L11 & Negatif & Negatif & Positif & Positif 1 & Negatif \\
\hline PH - L13 & Positif & Negatif & Positif & Positif 2 & Negatif \\
\hline PI - L16 & Negatif & Negatif & Positif & Positif 1 & Negatif \\
\hline PJ - L17 & Positif & Positif & Positif & Positif 3 & Positif \\
\hline PK - L19 & Negatif & Negatif & Negatif & Negatif & Negatif \\
\hline$P L-L 20$ & Negatif & Negatif & Negatif & Negatif & Negatif \\
\hline
\end{tabular}

Berdasarkan hasil uji organoleptik dengan uji laboratorium pada tabel 3, terdapat 2 sampel nugget berlabel yang positif 3 memiliki kecocokan dengan hasil uji laboratorium, sedangkan 1 sampel nugget berlabel yang positif 2 dengan kode sampel PC - L3 memiliki ciri fisik berbentuk kenyal dan padat serta berbau tidak alami memiliki kecocokan dengan hasil laboratorium. Untuk 3 nugget berlabel yang positif 1 tidak memiliki kecocokan dengan hasil laboratorium, hasil laboratorium menyatakan bahwa nugget negatif boraks / tidak mengandung boraks. 
Tabel 4

Hasil Uji Organoleptik dengan Uji Laboratorium Terhadap Kandungan Boraks Pada Nugget Ayam Curah yang Dijual Di Pasar Tradisional Surabaya Tahun 2013

\begin{tabular}{|c|c|c|c|c|c|}
\hline \multirow[b]{2}{*}{ Kode Sampel } & \multicolumn{3}{|c|}{ Ciri-ciri Kandungan Boraks pada Nugget Curah } & \multirow{3}{*}{$\begin{array}{l}\text { Hasil } \\
\text { Pemeriksaan } \\
\text { Secara Fisik } \\
\text { Positif } 1\end{array}$} & \multirow[b]{2}{*}{$\begin{array}{l}\text { Hasil Uji } \\
\text { Laboratorium }\end{array}$} \\
\hline & $\begin{array}{l}\text { Berbentuk Kenyal } \\
\text { dan Padat (Tidak } \\
\text { mudah hancur) }\end{array}$ & $\begin{array}{l}\text { Berbau tidak alami } \\
\text { (daging ayam) } \\
\text { atau apek }\end{array}$ & $\begin{array}{l}\text { Bewarna lebih } \\
\text { kusam dari } \\
\text { warna asli }\end{array}$ & & \\
\hline PA - C1 & Positif & Negatif & Negatif & & Negatif \\
\hline PB - C2 & Negatif & Positif & Negatif & Positif 1 & Negatif \\
\hline PC - C3 & Positif & Positif & Positif & Positif 3 & Positif \\
\hline PD - C4 & Positif & Positif & Negatif & Positif 2 & Negatif \\
\hline PE - C5 & Negatif & Negatif & Negatif & Negatif & Negatif \\
\hline PF - C6 & Positif & Positif & Positif & Positif 3 & Positif \\
\hline PG - C7 & Positif & Negatif & Negatif & Positif 1 & Negatif \\
\hline $\mathrm{PH}=\mathrm{C} 8$ & Positif & Positif & Positif & Positif 3 & Positif \\
\hline PI - C9 & Negatif & Negatif & Negatif & Negatif & Negatif \\
\hline PJ - C10 & Positif & Positif & Negatif & Positif 2 & Negatif \\
\hline PK - C11 & Positif & Positif & Negatif & Positif 2 & Negatif \\
\hline $\mathrm{PL}-\mathrm{C} 12$ & Positif & Positif & Negatif & Positif 2 & Negatif \\
\hline PM - C13 & Positif & Positif & Negatif & Positif 2 & Negatif \\
\hline$P N-C 14$ & Positif & Positif & Positif & Positif 3 & Positif \\
\hline PO - C15 & Negatif & Negatif & Negatif & Negatif & Negatif \\
\hline PP - C16 & Positif & Positif & Positif & Positif 3 & Positif \\
\hline PQ - C17 & Positif & Positif & Positif & Positif 3 & Positif \\
\hline PR - C18 & Positif & Positif & Negatif & Positif 2 & Negatif \\
\hline PS - C19 & Negatif & Positif & Positif & Positif 2 & Positif \\
\hline PT - C20 & Negatif & Negatif & Negatif & Negatif & Negatif \\
\hline
\end{tabular}

Pada tabel 4, terdapat 6 sampel positif 3 memiliki kecocokan dengan hasil laboratorium. Dari 7 sampel nugget curah yang dinyatakan positif 2, sampel dengan kode PS - C19 dengan ciri berbau tidak alami dan bewarna lebih kusam memiliki kecocokkan dengan hasil laboratorium.

Sedangkan 3 sampel nugget curah yang positif 1 tidak memiliki kecocokan dengan hasil laboratorium, hasil laboratorium menyatakan nugget negatif boraks/ tidak mengandung boraks.

Boraks dilarang digunakan dalam makanan berdasarkan Peraturan Menteri Kesehatan RI No 722/ Menkes/ Per/ IX/ 1988. Apabila boraks masuk kedalam tubuh terus - menerus tanpa sepengetahuan konsumen akan terakumulasi dalam tubuh manusia dan menyebabkan keracunan kronis. Kematian pada orang dewasa dapat terjadi dalam dosis 15 - 25 gram, sedangkan pada anak dosis $5-6$ gram
(Cahyadi, 2008). Umumnya, produsen menambahkan boraks untuk meningkatkan kekenyalan, darı kepadatan pada tekstur makanan. (Saparinto, 2006). Terutama pada nugget curah yang merupakan nugget yang dijual secara eceran, tidak menutup kemungkinan produsen menambahkan boraks kedalam nugget. Menurut hasil wawancara, $85 \%$ nugget curah lebih disukai oleh konsumen terutama dari kalangan ibu rumah tangga, dengan rata rata jumlah nugget yang disediakan $4-10$ bungkus nugget curah maka semakin sering pengiriman nugget, sedangkan nugget tersebut mengandung boraks akan berdampak terhadap kesehatan masyarakat sekitar sebab kualitas makanan yang dijual di pasar berisiko terhadap kesehatan masyarakat (Rositasari, 2012).

Sehingga masyarakat harus lebih cermat dalam memilih nugget yang sehat dengan mengenali ciri-ciri nugget yang 
mengandung boraks, sebab tidak hanya nugget curah yang mengandung boraks, tetapi nugget berlabel pun juga menggunakan boraks. Untuk Dinas PD Pasar Surya dan Pengelola Pasar di pasar swasta disarankan melakukan pemeriksaan makanan secara berkala melalui kerjasama dengan dinas yang berwenang untuk melakukan pemeriksaan makanan

Hasil penelitian ini juga dapat digunakan sebagai referensi atau memperluas penelitian yaitu melakukan studi kualitatif kandungan boraks pada makanan lain atau melakukan eksperimen untuk menjaga keawetan makanan dengan menggunakan bahan lain yang lebih aman daripada menggunakan boraks.

\section{Kesimpulan dan Saran \\ Kesimpulan}

1. Dari hasil pemeriksaan kondisi fisik nugget berlabel diperoleh hasil bahwa 2 sampel $(16,6 \%)$ dinyatakan positif 3,2 sampel $(16,6 \%)$ dinyatakan positif 2,3 sampel $(25 \%)$ dinyatakan positif 1 , dan 5 sampel $(41,6 \%)$ dinyatakan negatif. Untuk nugget curah, 6 sampel $(30 \%)$ diyatakan positif 3,7 dinyatakan positif 2,3 sampel (25\%) dinyatakan positif 1 , dan 4 sampel $(41,6 \%)$ dinyatakan positif.

2. Dari hasil pemeriksaan laboratorium menggunakan metode uji kertas kurkumin dapat diketahui bahwa 3 sampel $(25 \%)$ nugget berlabel positif mengandung boraks dan 7 sampel (35\%) nugget curah positif mengandung boraks.

\section{Saran}

1. Bagi pengelola pasar tradisional

Melakukan kerjasama dengan dinas terkait yang berwenang untuk melakukan pemeriksaan makanan.

2. Bagi Instansi Terkait

Disarankan bagi Dinas Kesehatan untuk melakukan pemeriksaan makanan pada nugget ayam curah dan untuk BPOM melakukan pengawasan pada nugget ayam berlabel.
4. Bagi peneliti lain

Disarankan untuk melakukan studi kualitatif pada makanan lain atau melakukan eksperimen untuk menjaga keawetan makanan menggunakan bahan yang lebih aman.

\section{DAFTAR PUSTAKA}

Adiwisastra, A. 1992. Keracunan Sumber, Bahaya, Serta Penganggulangannya. Bandung, Angkasa.

Badan Standarisasi Nasional. 2002. SNI 016683-2002 - Naget Ayam (Chicken Nugget). Jakarta

Cahyadi, Wisnu. 2008. Analisis dan Aspek Kesehatan : Bahan Tambahan Pangan. Jakarta, Bumi Aksara.Edisi kedua

Cahyadi, Wisnu, 2006. Analisis dan Aspek Kesehatan : Bahan Tambahan Pangan. Jakarta, Bumi Aksara.

Notoatmodjo, Soekidjo, 2010. Metodologi Penelitian Kesehatan. JaRarta, Rineka Cipta.

Peraturan Menteri Kesehatan Nomor 1168 Tahun 1999 Lampiran II Tentang Bahan Tambahan yang Dilarang Digunakan Dalam Makanan.

Peraturan Menteri Kesehatan Nomor 722 Tahun 1988 Tentang Bahan Tambahan Makanan.

Purnawijayanti, Hiasinta A. 2001. Sanitasi, Higiene, dan Keselamatan Kerja dalam Pengolahan Makanan. Jogyakarta, Kanisius : 68

Rositasari, Estiyana. 2012. Kandungan Boraks Pada Nugget Curah Yang Dijual Dipasar Tradisional Diwilayah Kabupaten Sidoarjo Tahun 2012. Surabaya, Kesehatan Lingkungan Surabaya.

Saparinto, C., Hidayati, Diana. 2006. Bahan Tambahan Pangan. Jogyakarta, Kanisius: $60-62$

3. Bagi Masyarakat

Dalam memilih nugget, hendaknya mengenali ciri - ciri nugget yang mengandung borak. 